\title{
AMPLITUDO OSILASI POSISI DOMAIN WALL BAHAN FEROMAGNETIK NANOWIRE BERKONTRIKSI SEGITIGA KETIKA DIBERI MEDAN LUAR AC DENGAN AMPLITUDO 2 MILITESLA
}

\author{
W. Nursiyanto ${ }^{1, a)}$, B. Soegijono ${ }^{2, b)}$, E. Djatmiko ${ }^{1, \mathrm{c})}$ \\ ${ }^{1}$ Program Studi Teknik Mesin, Universitas Pancasila, Srengseng Sawah, Jagakarsa, Jakarta 12640 \\ 2Program Studi Ilmu Material, Universitas Indonesia, Jl. Salemba Raya No.4, Jakarta 10430
}

Email: a)widianursiyanto@gmail.com, b)bambangsg11@yahoo.com, c)eddydjatmiko@gmail.com.

\begin{abstract}
Abstrak
Banyak para peneliti menyoroti bahan feromagnetik bentuk nanowire dalam kaitan dengan aplikasi magnetic storage, sebagai penyimpan data berbasis magnet. Oleh karena itu, telah dilakukan pengamatan amplitudo osilasi domain wall (DW) pada bahan feromagnetik nanowire berukuran $2000 \times$ $200 \times 5 \mathrm{~nm} 3$ dengan kontriksi (notch) simetri berbentuk segitiga yang diberi medan magnet luar AC dengan amplitudo 2,0 $m T$ dan variasi frekuensi dari 0,3 GHz sampai 2,0 $\mathrm{GHz}$. Diperoleh data yang berasal dari operasi simulasi mikromagnetik dengan menggunakan perangkat lunak bernama "Object Oriented Micromagnetic Framework" (OOMMF) berdasarkan persamaan dinamika spin magnet Landau-Lifshitz-Gilbert (LLG). Hasil pengolahan data pengamatan memperlihatkan bahwa osilasi DW memiliki frekuensi yang sama dengan frekuensi medan magnet luar yang diberikan. Posisi DW untuk bahan Fe tidak mengalami pergeseran dan menghasilkan nilai amplitudo DW yang stabil. Sedangkan bahan Ni dan Co mengalami pergeseran dari posisi ekuilibrium yaitu ke arah sumbu xpositip dan nilai amplitudo DW semakin kecil dengan meningkatnya frekuensi medan luar.
\end{abstract}

Kata-kata kunci: feromagnetik, nanowire, notch, osilasi, amplitudo.

\begin{abstract}
Many researchers interested to know about the nanowire ferromagnetic material for the application of magnetic storage as magnet-based data storage. Therefore, it has been observed amplitude of the domain wall oscillation in the nanowire ferromagnetic material by dimension of $2000 \times 200 \times 5 \mathrm{~nm}^{3}$ have given the symmetrical triangular notch in the center. After that, external magnetic field with amplitude of $2.0 \mathrm{mT}$ and variation of frequency from $0.3 \mathrm{GHz}$ to $2.0 \mathrm{GHz}$ given to the sample. The data get from micro magnetic simulation by using software called "Object Oriented Micro Magnetic Framework" (OOMMF) which it working based on magnetic spin dynamics equation of LandauLifshitz-Gilbert (LLG). The results showed that oscillations DW have same number with frequency of the external magnetic field. For Fe material, DW position does not shift from the position of equilibrium and produce amplitude of DW almost stable. While for the material $\mathrm{Ni}$ and $\mathrm{Co}$, the result was different showed that position of DW have shifted to the $\mathrm{x}$-axis positive and have amplitude tend smaller when the frequency of the external field increased.
\end{abstract}

Keywords: ferromagnetic, nanowire, notch, oscillation, amplitude. 


\section{PENDAHULUAN}

Akhir-akhir ini, para ilmuan terfokus pada bahan feromagnetik dalam penelitiannya. Hal ini disebabkan potensi bahan feromagnetik untuk diaplikasikan dalam perangkat spintronik (spintronic device) yaitu media penyimpan berbasis magnetik (magnetic storage), dan sensor berbasis magnetik (magnetic sensor) cukup besar. [1].

Salah satu penelitian feromagnetik bentuk nanowire diaplikasikan sebagai media penyimpan yaitu magnetic domain-wall racetrack memory (RM). RM ini terbuat dari bahan feromagnetik Permalloy yang mampu membawa 10 sampai 100 buah dinding domain (domain wall) dalam lebar nanowire sebesar $100 \mathrm{~nm}$ [2].

Bahan feromagnetik nanowire telah banyak dieksplorasi dalam beberapa tahun terakhir untuk realisasi perangkat yang didasarkan pada pemahaman dan pengendalian DW seperti logika magnetik, penginderaan dan perangkat memori [3-6]. Salah satu metode pengendalian DW yang paling layak yaitu menempatkan notch pada bahan magnetic nanowire [7-12].

Secara umum, notch yang lebih lebar memberikan stabilitas yang lebih baik terhadap fluktuasi termal, tetapi membutuhkan medan magnet yang lebih besar untuk memicu gerakan DW [11]. Hal ini disebabkan karena energi DW pada notch lebih rendah dari daerah yang tanpa notch.

Dalam penelitian ini, bahan feromagnetik nanowire dengan notch simetri berbentuk segitiga di tengahnya yang pada keadaan awal memiliki konfigurasi head-to-head seperti ditunjukkan pada Gambar 1, diberikan medan magnet luar yang sejajar dengan nanowire untuk mengetahui osilasi posisi DW dan besarnya amplitudo osilasi.

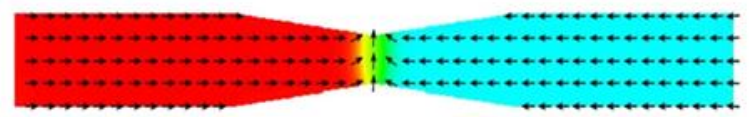

GAMBAR 1. Konfigurasi head to head pada fero-magnetik nanowire [6]

\section{METODE PENELITIAN}

Penelitian dilakukan dengan metode simulasi yang menggunakan perangkat lunak domain publik OOMMF [13], yang akan diperoleh data osilasi DW dari bahan feromagnetik nanowire berdasarkan persamaan Landau-Lifshitz-Gilbert [14].

$$
\frac{d M}{d t}=-\frac{|y|}{\left(1+\alpha^{2}\right)} M x H_{e f f}-\frac{|y| \alpha}{\left(1+\alpha^{2}\right)} \frac{M}{M_{s}} x\left(M x H_{e f f}\right)
$$

dengan nilai $\boldsymbol{H}_{\text {eff }}$ :

$$
H_{\text {eff }}=H_{\text {applied }}+H_{\text {demag }}+H_{\text {uniso }}+H_{\text {exchange }}
$$

Bahan feromagnetik nanowire yang digunakan memiliki dimensi $2000 \times 200 \times 5 \mathrm{~nm}^{3}$ yang diberi notch segitiga simetri ditengahnya seperti terlihat pada Gambar 2. Ukuran sel simulasi mikromagnetik adalah 2,5 $\times 2,5 \times 2,5 \mathrm{~nm}^{3}$ dan nilai konstanta redaman $\alpha$ dalam persamaan LandauLifshitz-Gilbert dipilih 0,01.

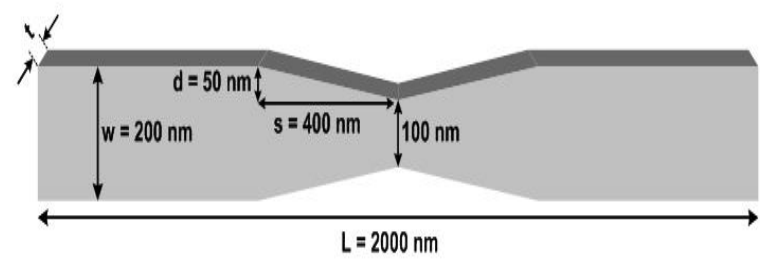

GAMBAR 2. Dimensi feromagnetik nanowire dengan notch segitiga. [15] 
Digunakan medan magnet luar bolak-balik dengan amplitudo $A=2,0 \mathrm{mT}$ dan variasi frekuensi: $f=0,3 ; 0,5 ; 0,7 ; 0,9 ; 1,0$ dan $2,0 \mathrm{GHz}$, berdasarkan persamaan:

$$
H_{\text {applied }}(t)=A \sin (2 \pi f t)
$$

\section{HASIL DAN PEMBAHASAN}

Kurva posisi DW bahan Fe dengan notch segitiga terlihat bahwa frekuensi posisi DW memiliki jumlah yang sama dengan frekuensi medan bolak-balik (Gambar 3). Posisi DW bergerak sepanjang nanowire mengalami redaman yang semakin besar ketika frekuensi medan magnet bolak-balik semakin tinggi.
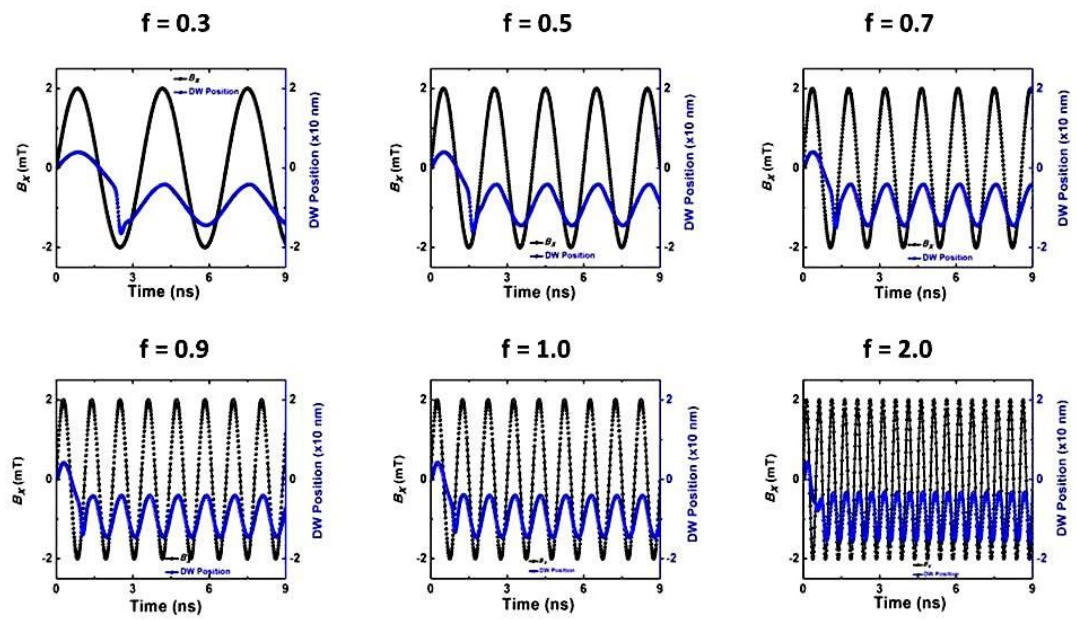

GAMBAR 3. Osilasi posisi DW bahan Fe

Pada bahan Ni juga terlihat bahwa frekuensi dan amplitudo medan luar AC sangat berpengaruh terhadap osilasi DW. Dari Gambar 4 terlihat bahwa frekuensi posisi DW memiliki jumlah yang sama dengan frekuensi medan bolak balik.

$f=0.3$

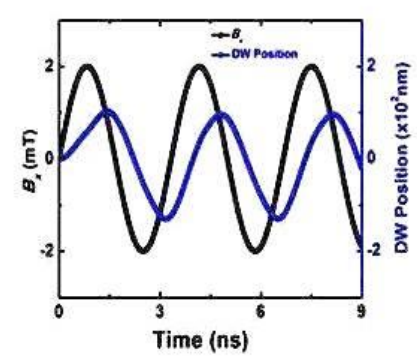

$f=0.9$

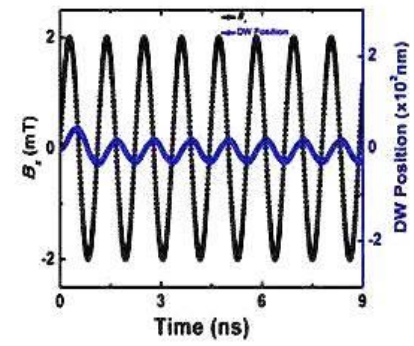

$f=0.5$

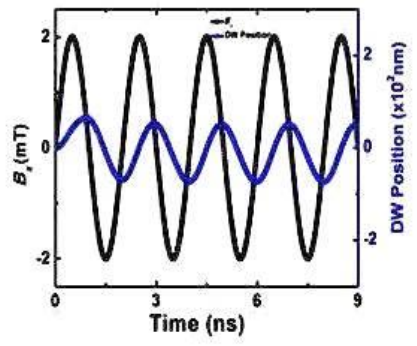

$f=1.0$

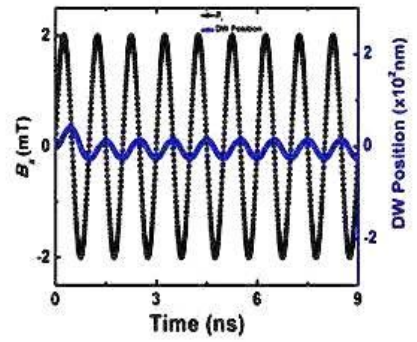

$f=0.7$

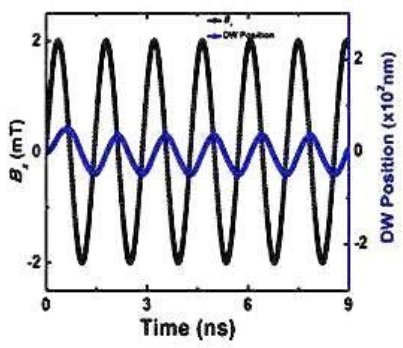

$\mathrm{f}=\mathbf{2} .0$

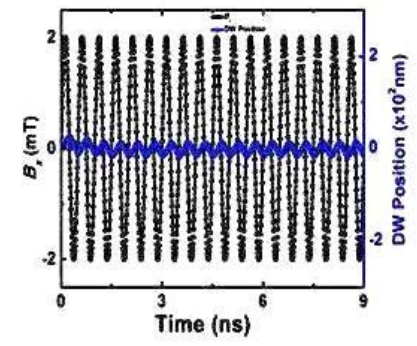


GAMBAR 4. Osilasi posisi DW bahan Ni

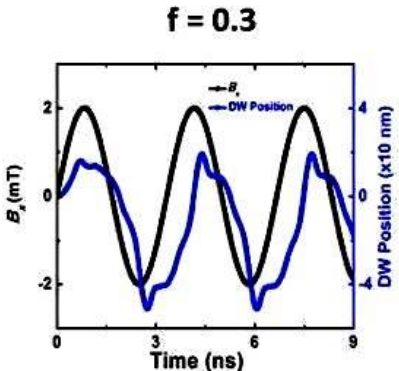

$f=0.9$

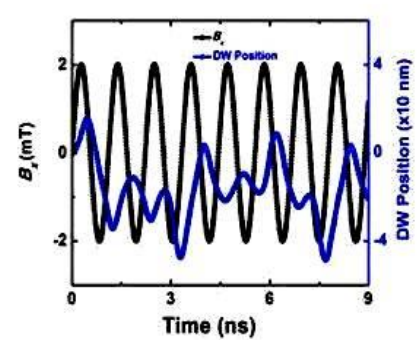

$f=0.5$

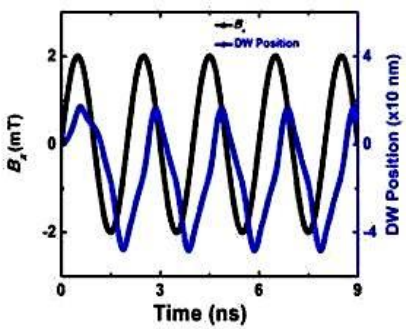

$\mathbf{f}=\mathbf{1 . 0}$

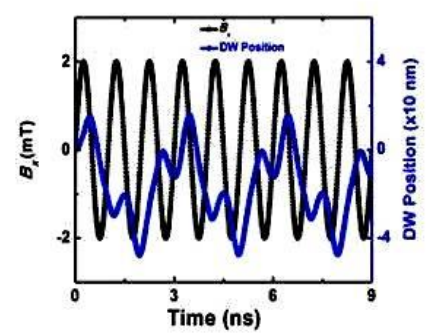

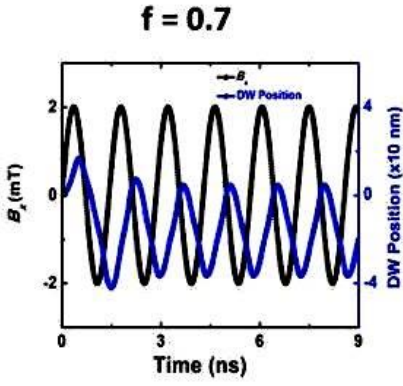

$\mathbf{f}=\mathbf{2 . 0}$

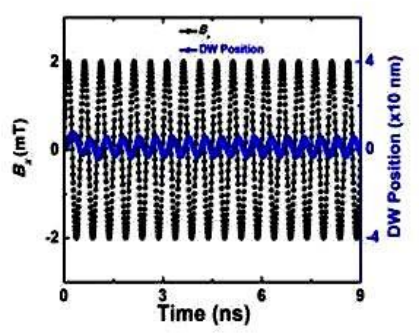

GAMBAR 5. Osilasi posisi DW bahan Co

Pada Gambar 5 terlihat bahwa bahan Co juga memiliki jumlah frekuensi posisi DW yang sama dengan frekuensi medan bolak-balik.

Dengan menggabungkan kurva posisi DW akibat adanya medan magnet yang memiliki variasi frekuensi dikenakan pada bahan $\mathrm{Fe}$, Ni dan Co dapat dibuat kurva amplitudo posisi DW Vs frekuensi seperti terlihat pada Gambar 6.
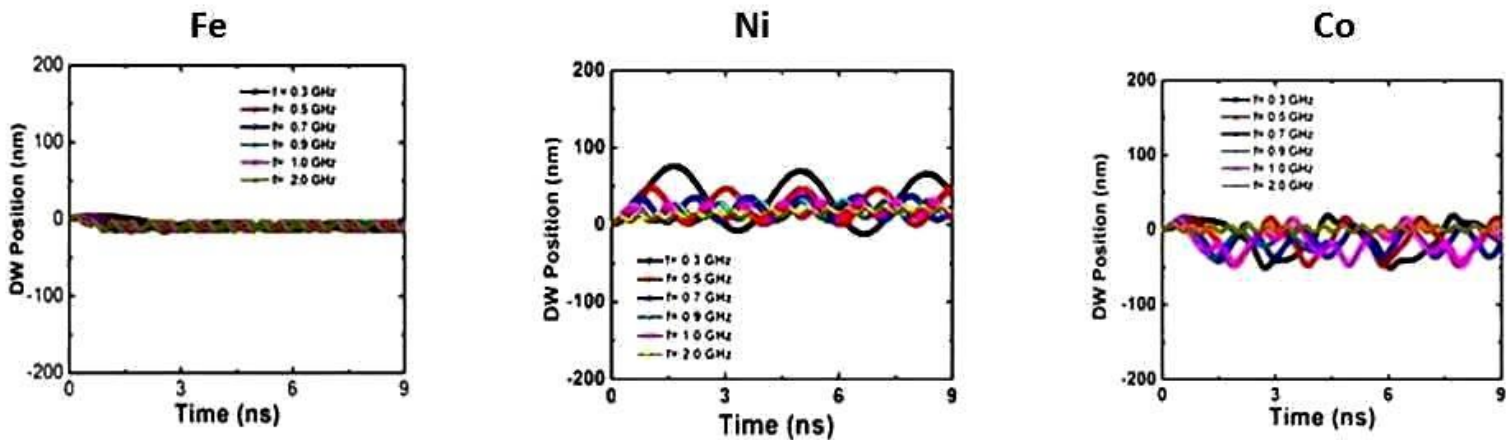

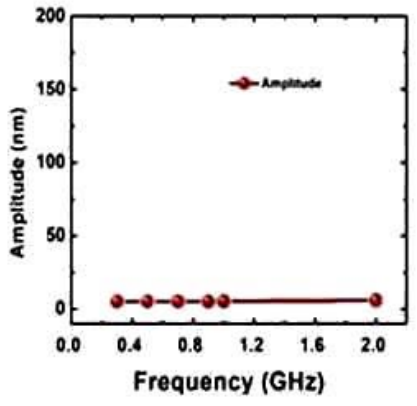

a

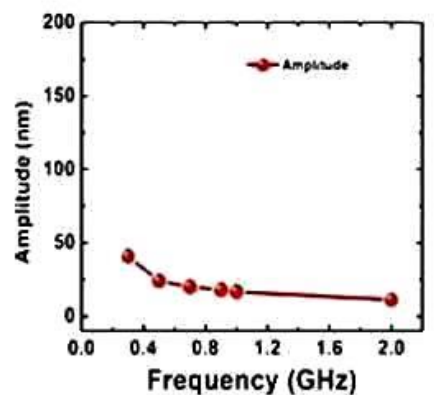

b

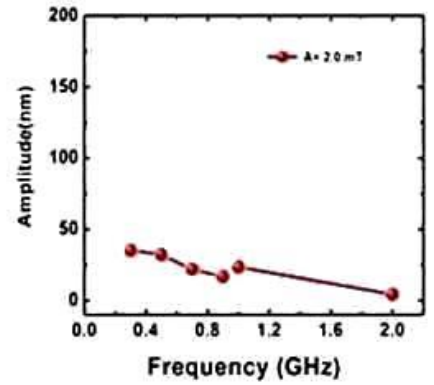

C 
GAMBAR 6. Osilasi posisi DW dan amplitudo bahan (a) Fe, (b) Ni dan (c) Co

Besar amplitudo pada bahan Fe cenderung konstan ketika frekuensi medan bolak-balik meningkat. Namun pada bahan Ni dan Co amplitudonya cenderung menurun ketika frekuensi yang diberikan semakin besar. (lihat Tabel 1).

TABEL 1. Amplitudo posisi DW pada bahan $\mathrm{Fe}$, Ni dan Co dengan variasi frekuensi.

\begin{tabular}{cccc}
\hline \multirow{2}{*}{$\mathbf{f}(\mathbf{G H z})$} & \multicolumn{3}{c}{ Amplitudo (cm) } \\
\cline { 2 - 4 } & $\mathbf{F e}$ & $\mathbf{N i}$ & $\mathbf{C o}$ \\
\hline 2,0 & 9,5 & 13,2 & 9,5 \\
1,0 & 9,3 & 15,8 & 25,1 \\
0,9 & 9,3 & 20,3 & 20,1 \\
0,7 & 9,3 & 23,1 & 23,2 \\
0,5 & 9,3 & 25,2 & 34,3 \\
0,3 & 9,4 & 40,4 & 36,6 \\
\hline
\end{tabular}

\section{SIMPULAN}

Bahan Fe menghasilkan posisi DW yang tidak mengalami pergeseran dan besarnya amplitudo DW cukup stabil. Sedangkan bahan Ni dan Co menghasil-kan posisi DW yang mengalami pergeseran dari posisi ekuilibrium ke arah sumbu x-positip dan besar amplitudo DW semakin kecil dengan meningkatnya frekuensi medan luar.

\section{REFERENSI}

[1] Wolf, S. A. et al. Spintronics: A spin-based electronics vision for the future, Science 294, (2001), p. 1488.

[2] Parkin, S. S., Hayashi, M., dan Thomas, L. Magnetic domain wall racetrack memory, Science 320, (2008), p. 190.

[3] R.P. Cowburn and D. Petit, Spintronics: Turbulence ahead, Nat. Mater. 4, (2005), p. 721.

[4] D.A. Allwood, G. Xiong, M.D. Cooke, C.C.. Faulkner, D. Atkinson, N. Vernier, and R.P. Cowburn, Submicrometer Ferromagnetic NOT Gate and Shift Register, Science 296, (2002), p. 2003

[5] D.A. Allwood, G. Xiong, C.C.. Faulkner, D. Atkinson, D. Petit, and R.P. Cowburn, Magnetic Domain-Wall Logic Science 309, (2005), p. 1688.

[6] D. Djuhana, H.-G. Piao, S.-H. Lee, D.-H. Kim, S.-M. Ahn, and S.-B. Choe, Oscillatory transformative domain wall inner structure of the depinning domain wall around a notched ferromagnetic wire, Appl. Phys. Lett. 97, (2010), p. 022511.

[7] M. Tsoi, R. E. Fontana, and S. S. Parkin, Dynamics of Domain Wall Motion in Wires with Perpendicular Anisotropy, Appl. Phys. Lett. 83, (2003), p. 2617.

[8] J. Grollier, P. Boulenc, V. Cros, A. Hamzi, A. Vaures, A. fert, and G. Faini, Switching a spin valve back and forth by current-induced domain wall motion, Appl. Phys. Lett. 83, (2003), p. 509.

[9] C. K. Lim, T. Devolder, C. Chappert, J. Grollier, V. Cros, A. Vaures, A. Fert, and G. Faini, Domain wall displacement induced by subnanosecond pulsed current, Appl. Phys. Lett. 84, (2004), p. 2820.

[10] S. Lepadatu and J. B. Xu, Direct observation of domain wall scattering in patterned Ni80 Fe20 and Ni nanowires by current-voltage measurements,Phys. Rev. Lett. 92, (2004), p. 127201

[11] M. Klaui, H. Ehrkc, U. Rudiger, T. Kasama, R. E. Dunin-Borkowski, D. Backes, L.J. Heyderman, C. A. F. Vaz, J. A. C. Bland, G. Faini, E. Cambril, and W. Wernsdorfer, Direct observation of domain-wall pinning at nanoscale constrictions, Appl. Phys. Lett. 87, (2005), p. 102509. 
[12] K.-J. Kim, C.-Y. You, S.-B.itu Choe, Numerical Formula of Depinning Fields from Notches in Ferromagnetic Permalloy Nanowire, Journal of Magnetics 13(4), (2008), p. 136-139.

[13] M.J. Donahue and D.G. Porter, OOMMF User's Guide [Online]. Available:

http://math.nist.gov/oommf (2002).

[14] T.L. Gilbert, A phenomenological theory of damping in ferromagnetic materials, IEEE Trans. Magn. 40(6), (2004), p. 3443-3449.

[15] D. Djuhana, H. G. Piao, J. H. Shim, S. H. Lee, D. H. Kim, S. M. Ahn, and D. H. Kim, Interaction of antiparallel transverse domain walls in ferromagnetic nanowires. Journal of Nanoscience and Nanotechno-logy Vol. 11, (2011) p.6237-6240.

[16] W. Nursiyanto, B. Soegijono, D. Djuhana, dan L. Rohman, Investigasi Osilasi, Struktur dan Lebar Domain Wall di Sekitar Notch Segitiga dan Lengkung Pada Fe Nanowire Akibat Medan Luar (AC Field), Prosiding Seminar Fisika ISSN 2339-0654, (2014), p. 306-308.

[17] W.Nursiyanto, Analisis Osilasi dan Struktur Domain Wall di Dalam Kontriksi Notch Pada Bahan Feromagnetik (Fe, Co, Ni) Berbentuk Nanowire, Disertasi, Universitas Indonesia, (2014). 